\title{
Historias detrás de objetos: organizadores y vendedores en un circuito de eventos
}

\author{
María Cecilia Díaz ${ }^{12}$ \\ ' Conselho Nacional de Investigações Científicas e Técnicas (CONICET), Argentina \\ ${ }^{2}$ Centro de Investigações da Faculdade de Filosofia e Humanidades, \\ Universidade Nacional de Córdoba (FFyH/UNC), Argentina
}

\section{Resumen}

Este artículo sigue una línea de estudios según la cual la creación de mundos sociales es constitutiva de los modos de consumo desarrollados por las comunidades de fans. Aquí se describe un circuito de eventos que reunía a fans de la cultura pop japonesa entre los años 2009 y 2013 en la ciudad de Córdoba, Argentina, y se propone un desplazamiento hacia el estudio de procesos de construcción de sí de quienes se desempeñaban como vendedores y organizadores en tales instancias de encuentro. El enfoque presentado considera como fundamentales las reflexiones que los interlocutores de la pesquisa realizaban acerca del pasaje entre hobby y trabajo implicado en la profesionalización de sus prácticas. En este sentido, el análisis de las narrativas muestra que la profesionalización constituye un proceso continuo en el cual ciertas actividades consideradas de ocio o de tiempo libre se tornan proyectos laborales, a partir de la transformación de los vínculos de atracción y apego que unen a los fans con los objetos que producen y comercializan.

Palabras clave: fans, animé, hobby, trabajo. 


\section{Histórias por trás de objetos: vendedores e organizadores em um circuito de eventos}

\section{Resumo}

Este artigo continua uma linha de estudos que afirma que a criação de mundos sociais é constitutiva dos modos de consumo desenvolvidos pelas comunidades de fãs. Aqui se descreve um circuito de eventos que reunia fãs da cultura pop japonesa entre os anos 2009 e 2013 em Córdoba, Argentina, e se propõe um deslocamento para o estudo dos processos de construção de si das pessoas que desempenhavam atividades de vendedores e organizadores nessas instâncias de encontro. $O$ foco apresentado considera fundamentais as reflexões que os interlocutores da pesquisa faziam acerca da passagem de um hobby para um trabalho envolvida na profissionalização das suas práticas. Nesse sentido, a análise das narrativas revela que a profissionalização constitui um processo contínuo no qual certas atividades consideradas de lazer ou de tempo livre se tornam projetos laborais a partir da transformação dos vínculos de atração e apego que unem os fãs com os objetos produzidos e vendidos por eles.

Palavras-chave: fãs, animê, hobby, trabalho. 


\title{
Historias detrás de objetos: organizadores y vendedores en un circuito de eventos
}

\author{
María Cecilia Díaz
}

“... the lines between creators and consumers have been very permeable, and today's fanboy reader may be tomorrow's writer, artist, editor or publisher"

Bukatman, Scott (1992)

\section{Introducción}

Durante mi trabajo de campo para una pesquisa desarrollada entre 2009 y 2013, participé de numerosos eventos de animé en la ciudad de Córdoba, Argentina, en los que se celebraba el gusto compartido por la "cultura pop japonesa” (Luyten, 2006). Éstos se realizaban los fines de semana, por lo general en locales bailables o asociaciones de socorros mutuos, y duraban todo el día. El programa incluía concursos de dibujo de estilo manga (historietas japonesas), exhibiciones de artes marciales y de coreografías grupales, torneos de juegos y, finalmente, el concurso de cosplay, ${ }^{3}$ esto es, un desfile en el que participaban los asistentes que habían acudido caracterizados como personajes de animé (animación japonesa). Además de estas actividades, había numerosos puestos de venta de mercancías de diversa índole: remeras estampadas con imágenes de personajes, tazas, pins (prendedores), figuras coleccionables, accesorios, llaveros, pelucas, lapiceras, cuadernos, muñecos de peluche, DVD de series y películas, revistas, juegos de mesa y cartas, comida asiática, etc.

En una ciudad que se caracteriza por su intensa vida universitaria, los eventos reunían en promedio a quinientos niños y jóvenes que acudían solos, con sus padres y/o con amigos, para pasar el día y encontrarse, motivados por un conjunto de productos culturales que los fascinaban. Una de las impresiones más duraderas que me dejó la experiencia de recorrer los salones alquilados para tales ocasiones fue que se trataba de ámbitos en los cuales muchas de las interacciones estaban guiadas por la comercialización de los productos previamente descritos. En efecto, la organización del espacio en cada evento imponía ciertos modos de estar, a través de la presencia de stands (puestos de venta), que consistían en mesas dispuestas a lo largo de las paredes de los salones -o boliches, es decir, locales bailables- alquilados para esas ocasiones. De esta manera, se proponía a los asistentes un recorrido específico, un camino a seguir en la búsqueda de algo deseado desde hacía mucho

\footnotetext{
Una primera versión de este artículo fue presentada en la X Reunión de Antropología del Mercosur (X RAM, 2013) y luego formó parte de mi disertación de maestría, defendida en el Programa de Pós-Graduação em Antropologia Social, Museu Nacional, Universidade Federal do Rio de Janeiro (PPGAS-MN/UFRJ), bajo la orientación del Dr. Luiz Fernando Dias Duarte (2014). Esta pesquisa se vio beneficiada por las discusiones en el marco del Programa "Subjetividades y Sujeciones Contemporáneas” (Centro de Investigaciones de la Facultad de Filosofía y Humanidades - CIFFyH), dirigido por el Dr. Gustavo Blázquez - quien orientó mi trabajo final de grado- y codirigido por la Dra. María Gabriela Lugones, a quien agradezco por la lectura del presente texto y las sugerencias recibidas. La Dra. Laura Belén Navallo Coimbra también realizó observaciones y comentarios que permitieron reforzar los argumentos que se articulan aquí. Los errores y omisiones, desde ya, son exclusiva responsabilidad de quien escribe.

2 A lo largo del texto opté por emplear itálica para los términos escuchados durante mi trabajo de campo -algunos de los cuales provienen del inglés o japonés-y comillas para los conceptos de la bibliografía consultada. En el caso de las expresiones breves de mis interlocutores, se combinarán ambos estilos. En las citas de fragmentos más extensos de entrevistas, el destacado es mío.

3 Cosplay, término que resulta de la unión de "costume" " “play"; es una práctica que consiste en encarnar a personajes de series y películas de animación japonesa, manga o cómics, por medio de trajes y maquillajes. También puede incluir la realización de performances en concursos, es decir, pequeñas secuencias de acción en las que se recrean momentos de los personajes en la ficción.
} 
tiempo, o que "llamara su atención" en ese momento en particular, como me fue dicho en numerosas entrevistas. Parte de las actividades que realizaban los asistentes giraba en torno a comprar productos y hablar entre sí sobre esas compras, mostrando a otros lo adquirido para luego recibir devoluciones y comentarios al respecto.

El crecimiento de un conjunto de circuitos que, siguiendo a Becker (2008) llamé "mundos del animé" en Córdoba, se dio en torno a la emergencia de esos emprendimientos comerciales. En stands en los eventos, los pequeños productores vendían aquello que conseguían importar, o que fabricaban, a compradores ávidos de conseguir esas mercancías. Los propios eventos formaban parte de estos emprendimientos y eran organizados por fans locales, que se nucleaban en un staff (equipo) destinado a posibilitar la emergencia y el desarrollo de esos momentos de reunión. En esta primera aproximación hacia los eventos locales y sus dinámicas, podemos percibir diferencias con respecto a las primeras convenciones organizadas a mediados de los 197os por los fans del manga y el animé en Japón que, de acuerdo con Schodt (1983), Papalini (2006) y Tamagawa (2012), tenían como objetivo principal la divulgación de historietas producidas por aficionados (dojinshi):

[Se trata de un] acontecimiento que se inició en diciembre de 1975, organizado por aficionados para aficionados, sin fines comerciales, llamado "Komiketto" (abreviación de "Comic Market”) que se repetía dos veces al año, en Tokio. (...) En Komiketto no se permite la participación de compañías editoriales ni de sponsors, lo cual mantiene su orientación hacia los aficionados (Papalini, 2006:38).

El tipo de formación que hemos analizado se encuentra más cerca de aquella observada por Lourenço (2009), quien analiza los eventos realizados en Rio de Janeiro y São Paulo como "loci de socialização e de familiarização com o mundo anime" (2009:239) a través de la compra o intercambio de objetos y el encuentro entre aficionados. ${ }^{4}$ Lamerichs (2013), por su parte, distingue formatos semejantes en su estudio comparativo del dojinshi y el cosplay en convenciones de Holanda, Estados Unidos y Alemania, a las que caracteriza como "sitios ejemplares (...) para participar en la cultura inspirada por el flujo mediático japonés" (2013: 157). De esto se desprende que las convenciones o eventos de animé constituyen instancias que se desarrollan con frecuencia desde la década de 1980 en distintas latitudes, lo que, ciertamente, ameritaría un estudio comparativo capaz de dar cuenta de sus singularidades y aspectos en común (Ito, 2012).

Un rasgo primordial de los eventos que abordo en este artículo es la combinación de la dimensión de compra y venta, y la presencia de espectáculos, tales como proyección de videos, concursos de cosplay y bandas que interpretaban los temas de apertura y final de las series de animé, conocidos como openings y endings. Uno de los integrantes del staff del evento Córdoba Animé Fest (CAF) se refería a esta figuración como la conjunción de dos etapas: "está la venta, donde todos pueden vender su merchandising y después lo que es la fiesta en sí, el cosplay, las bandas en vivo, las proyecciones." Otra entrevistada describía esas dos etapas con los términos de feria para designar los intercambios comerciales, y de entretenimiento para hacer alusión a lo que ocurría sobre el escenario del salón. Corresponde remarcar que, si bien las actividades del tipo "feria" seguían los ritmos de los compradores, las acciones propias del entretenimiento o espectáculo se realizaban según un cronograma fijado de antemano por los organizadores.

El evento constituía una mercancía cultural que posibilitaba la interconexión continua de las acciones y experiencias de sus participantes, de manera similar a lo que ocurría con los bailes de cuarteto estudiados por Blázquez (2009). Desde el año 2005 los eventos eran organizados por fans para fans, y unos años después apareció la figura del inversor, que se ocupaba de contratar a miembros del staff de otros eventos o a personas con una cierta experiencia en el ambiente para que se desempeñaran como organizadores, a cambio de una remuneración. Tal es el caso del evento Animé Shock, realizado por primera vez en abril de 2013, cuya producción corría por cuenta de un boliche céntrico y su organización se encontraba a cargo de quienes integraban el staff de un

4 A diferencia de los mundos que se describen aquí, los lugares elegidos por los organizadores en los casos analizados por Lourenço (20og) eran clubes y escuelas. 
evento anterior. Daniela, ${ }^{5}$ contratada bajo esta nueva modalidad, contaba cómo se produjo la transición que habilitó la vinculación de una empresa y la separación de las tareas de inversión y organización, antes reunidas en la figura del organizador:

... por lo general los que organizan son los que ponen el dinero. En este caso no, estamos separados en dos: está la gente que pone el dinero, que no tiene nada que ver con el palo [el ambiente], sino que invierte, y estamos nosotros que somos los organizadores del evento, por decirlo de alguna forma, los administradores, los que decimos "esto vale tanto" y ellos ponen la plata. Como ellos ponen la plata obviamente se quedan con el porcentaje total de las entradas y lo que ganan en la cocina. Y ellos a nosotros nos pagan un sueldo (Entrevista a Daniela, 11.04.13). ${ }^{6}$

Como podemos observar, inversores, organizadores, staff y vendedores se ocupaban de montar la escena de las convenciones locales, en la que coexistían distintos relatos acerca de sus motivaciones y aficiones. Aquí sigo el tipo de abordaje que propone Becker (2008:27), cuando sostiene que "al analizar un mundo de arte buscamos sus tipos característicos de trabajadores y el conjunto de tareas que cada uno de ellos realiza". En esta oportunidad, me interesa enfocar las prácticas de organización y venta de productos, que tornaban a los eventos en mercados donde los objetos que circulaban y la atracción que generaban hacían oscilar los valores de uso y de cambio de que estaban investidos (Hills, 2002). A la vez, las pasiones por esas mercancías impactaban en las historias particulares, y en los motivos para generar circuitos comerciales, y participar de los mismos. En este sentido, examinaré un repertorio de experiencias que comprende desde la organización y venta concebidas como hobbies, hasta los procesos de profesionalización que implicaban vender lo producido para "vivir de eso".

Con estos objetivos en mente, tomo como punto de partida el planteo de Turner (1977) acerca de la distinción entre trabajo [work] y ocio [leisure] en las sociedades industrializadas, que abriría espacio para los fenómenos liminoides de carácter fragmentario, plural y experimental, situados entre las ocupaciones y las actividades cívicas y familiares (1977:43). Curiosamente, la palabra leisure no solo deriva del latín "licere" - "permitir"-, sino también del indoeuropeo "leik" -"para ofrecer a la venta"- que alude, de acuerdo con Turner, al ámbito liminal del mercado "con sus implicaciones de elección, variación y contrato" (1977:43). Esa observación funcionará como guía para considerar las tensiones que se ponen en juego entre esas esferas de actividad, como así también para analizar las narrativas a la luz del continuum entre trabajo y hobby, 7 amor y dinero, que se pone de manifiesto en los eventos y en las concepciones de los que participan en ellos. Así, teniendo en cuenta el trazado etimológico que Turner realiza de la palabra leisure, propongo matizar las diferencias entre ocio y trabajo -o más específicamente, entre "actividades de tiempo libre" y "trabajo ocupacional", de acuerdo a Elias \& Dunning (1992:88)-y hacer hincapié en las continuidades mediante la metáfora del pasaje, del entre [betwixt and between] que impregna las experiencias de los fans una vez que éstos se abocan a la producción y venta de las mercancías culturales que aman.

\footnotetext{
En este trabajo opté por emplear seudónimos para referirme a algunas trayectorias puntuales.

Al momento de la entrevista, Daniela tenía 22 años y estudiaba Diseño de Modas en una universidad privada. Como en otros casos, la conocí en un evento de animé y allí determinamos los detalles para una posterior entrevista.

Según el diccionario de la Real Academia Española, "Hobby" es una "actividad que, como afición o pasatiempo favorito, se practica habitualmente en los ratos de ocio". Disponible en: <http://dle.rae.es/?id=KXu47LP>. Acceso en: 20/08/2013.
} 


\section{Consumir y producir: (re)situando las artes de hacer}

Antes de tratar sobre esos procesos, conviene hacer una breve digresión sobre trabajos que han explorado prácticas como las que se abordan aquí, dado que brindan herramientas analíticas útiles para pensar las experiencias de los fans en la conjunción entre consumo y producción. Me hago eco del abordaje de Hennion (2007), quien enfatiza la intensidad de las emociones que las personas sienten hacia los objetos que constituyen su pasión. Se vale para ello del término "amateur", que indica un compromiso sostenido en la realización de actividades sistemáticas que permiten desenvolver progresivamente un conjunto dado de sensibilidades y habilidades en las personas que las llevan a cabo. A propósito de los aficionados a la ópera, Benzecry (2012:34) considera al amor como un modo de construcción de sí que se produce en narrativas en las que la historia personal se encuentra atravesada por la relación con los objetos amados, permitiendo trazar el desarrollo individual de las pasiones y su proyección a futuro.

Al emplear el término "fan", recojo las observaciones de Jenkins (2010) acerca de la pertinencia del uso de "fan" en lugar de "fanatic", que incluye un componente de obsesión o de desmesura y que, en todo caso, habilita ciertas lecturas académicas centradas en reconocer la irracionalidad de los comportamientos de los sujetos en lugar de intentar estudiarlos en su complejidad. Si bien en las entrevistas aparecen estos instantes cuando los aficionados recuerdan períodos "de mayor fanatismo" o épocas en las que se empezaron a fanatizar, se trata precisamente de la construcción biográfica de momentos en los que la intensidad sentida hacia los diversos objetos se incrementó, y no de un estado emocional permanente. De la misma manera, hablar de "fan" o "fans" me permite abarcar, con una terminología cercana a fandom -término que apareció en el trabajo de campo y que significa "reino de fans"- un conjunto diverso de personas que se reunían en los eventos, y que compartían el gusto por el manga, el animé, los cómics, el rock y el pop japonés, las películas de superhéroes, los videojuegos y, también, los juegos de rol y cartas. Así, mis esfuerzos de pesquisa se centraron en el estudio de los eventos como situaciones en las que se realizaban, y visibilizaban, las redes de relaciones y las trayectorias apasionadas de los sujetos que participaban en ellas (Díaz, 2014). ${ }^{8}$ Las categorías identitarias empleadas para definir esas construcciones en ciertos momentos de la vida, tales como otaku y friki ${ }^{9}$, formaban parte de ese paisaje y se negociaban e intercambiaban también de manera situacional.

Valiéndose del modelo de lectura como cacería furtiva propuesto por De Certeau (2000 [1990]), Jenkins conceptualiza a los fans como piratas que "han desarrollado la piratería hasta convertirla en un arte" (2010:42), y añade: "La expresión "piratería" de De Certeau nos recuerda poderosamente los intereses potencialmente opuestos de los productores y consumidores, de los escritores y los lectores" (Jenkins, 2010:48). En su análisis, las prácticas enfocadas son la producción de literatura basada en los textos consumidos (fan fiction, fanzines), la creación de videoclips con imágenes de las series y música a elección (a la que denomina "videoarte"), y la composición musical que comenta textos preexistentes (filking). Estas producciones permiten explorar personajes o subtramas secundarias de las series, y circulan en una comunidad que se caracteriza por su gran dimensión participativa. De esta manera, para Jenkins los fans son prosumidores porque son a un tiempo consumidores y productores; $y$ las dos dimensiones no pueden ser pensadas por separado. Las convenciones, en tanto espacio de circulación, también son concebidas en la línea que contrapone y une a profesionales y fans:

\footnotetext{
8 En mi disertación de maestría exploro la idea de "trayectorias apasionadas" a partir de un estudio exhaustivo del desarrollo de pasiones y apegos por parte de fans de la cultura pop japonesa (Díaz, 2014). Dada la extensión de este artículo, sería imposible describir las trayectorias con la profundidad que merecerían. Por ese motivo, aquí circunscribo el análisis a las narrativas que recuperan los procesos de construcción de sí de un conjunto de organizadores y vendedores que daban forma a los mundos del animé en Córdoba entre 2009 y 2013.

9 "Otaku" es un término japonés que alude a las personas obsesionadas con cualquier tipo de práctica, aunque en otros países fue aplicado de manera general para designar a los fanáticos de la cultura pop japonesa (Cfr. Kelly, 2004). "Friki" deriva del inglés "freaky" e incluye las siguientes acepciones de acuerdo con la Real Academia Española: "1. Extravagante, raro o excéntrico. 2. Persona pintoresca y extravagante. 3. Persona que practica desmesurada y obsesivamente una afición.” Disponible en: <http://lema.rae.es/drae/?val=friki〉. Acceso en: 20/08/2013.
} 
A pesar de que las convenciones de ciencia ficción constituyen un mercado para los productos comerciales relacionados con las historias basadas en los medios de comunicación, y son un escaparate para escritores, ilustradores y artistas profesionales, las convenciones también constituyen un mercado para las obras producidas por los fans y una vitrina para los artistas fans." (Jenkins, 2010:65).

En la visión de Jenkins, los fans cuya labor se resalta son artistas del collage, piratas que ejercen su resistencia a través de asaltos sucesivos a los textos, y cuyos intereses se centran en la difusión de cintas de video y de sus propias obras, aun si no reciben compensaciones monetarias a cambio de ellas. Sin negar que esto sea así, Abercrombie y Longhurst reconocen que tales fans constituyen una muestra, en un espectro más amplio que incluiría desde una audiencia regular hasta pequeños productores (Gray, Sandvoss \& Harrington, 2007:8).

Otro conjunto de estudios problematiza las dimensiones de consumo y producción en torno a ejes críticos como la relación local/global y la extensión del fandom, en tanto modo distintivo de aproximación hacia objetos y formas de interacción social, en el marco del capitalismo global. Entre tales esfuerzos se puede ubicar el trabajo de Hills (2002), quien coloca la subjetividad imaginada de los fans en un proceso de permanente elaboración de distinciones entre prácticas de consumo "buenas" y "malas"; es decir, entre modos de acercamiento a los objetos más o menos auténticos, en los que impactan incluso las concepciones elaboradas por las ciencias sociales. En palabras del autor,

On the one hand, we are presented with a view of fans as (specialist) consumers, whose fandom is expressed through keeping up with new releases of books, comics and videos. On the other hand, we are told that fans whose practices are 'clearly linked with' dominant capitalist society (eg. They may be trying to sell videos recorded off-air) are likely to be censured within the fan culture concerned. This is not simply a theoretical contradiction: it is an inescapable contradiction which fans live out (Hills, 2002:5).

Aquí interesa particularmente retomar la idea de "artes de hacer" de De Certeau (2000), que tiene la virtud de enfocar los modos de usar los productos que se desarrollan en la vida cotidiana. A ello añadimos las contradicciones observadas por Hills, en la medida en que la pasión por objetos es habilitada -y se encuentra atravesada- por procesos de mercantilización y de construcción de distinciones nosotros/ellos (2002:37). En el contexto etnográfico que acompañara en la ciudad de Córdoba, los relatos sobre prácticas de compra e intercambio de objetos vinculados a la cultura pop japonesa aparecían, en comentarios y entrevistas, directamente asociados al período de fines de 1990 y comienzos de 200o. En este sentido, se correspondían con las derivas que realizaban los fans en busca de series y mangas, por kioscos, "comiquerías" y librerías de saldos del centro de la ciudad.

A partir de 2005, los eventos condensaron un circuito material y moral, en el que se anudaron progresivamente los procesos de producción de significados y las trayectorias de los distintos participantes. Se convirtieron, además, en espacios de circulación de aquellos objetos que durante los primeros años de formación del fandom local solo se conseguían a través de derivas céntricas. De manera paralela a la emergencia de los eventos, numerosos integrantes de esos mundos se embarcaron en la fabricación o venta de objetos, para obtener un ingreso extra o construir un proyecto dentro del "campo de posibilidades" abierto por esos consumos (Velho, 1981). Así, las "operaciones de los usuarios" (De Certeau, 2000:XLI), que primero se centraban en la compra de mercancías, pasaron a incluir su confección y producción.

Fruto de la gestión de los propios fans, los eventos siguieron esta tendencia y empezaron a ser organizados por distintos grupos, con el auspicio de los negocios vigentes. Estas actividades creaban "escenas locales" (Bennett \& Peterson, 2004) y ponían en juego prácticas de DIY (do it yourself) características tanto del bricolaje, como del punk y otros movimientos artísticos, que se valieron del collage como técnica para producir una cultura underground (Yúdice, 2007:27). Ese proceso se visualiza en la experiencia de Ana, una entrevistada que tenía 20 años cuando conversamos por primera vez y era estudiante universitaria. 
Ella había iniciado su participación en el circuito de eventos en 2010, y seis meses después había comenzado a vender fotos y prendedores artesanales en el Paseo Sobremonte -plaza céntrica donde se hacían reuniones todos los sábados- y en las convenciones. Ya en 2013, ella integraba el staff del evento Córdoba Animé Fest. El relato de ese camino recorrido tiene la virtud de mostrar las prácticas DIY que atravesaban el intercambio, la adquisición y/o producción de objetos para consumo personal; como también de revelar la aparición de proyectos de venta que servían para generar ingresos que luego podían invertirse en otras actividades del fandom:

... ahora empecé con el tema de las fotos a vender, pero ya hay gente que antes hacía cosas, por ejemplo, que hacía llaveritos o vinchitas, pero no habían decidido ir y venderlas directamente. (...) Las empecé haciendo para mí y después dije: “está buena la idea”. Primero, porque está bueno venderlo y segundo, porque no hay, vos vas a las casas de animé o de cómic en el centro y te venden los muñecos, te venden los mangas, los libros, las revistas, lo que sea, pero no hay imágenes del animé. A raíz de lo que yo hice, otras personas dijeron "voy a empezar a traer tal cosa que yo hacía". Con los chicos dijimos que está bueno porque hay algunos, por ejemplo, que están estudiando, son de la secundaria, y bueno, por ahí pueden hacer cositas y las venden, y les queda para ellos, digamos. Y aparte porque tratan siempre de buscar alguna fuente de dinero para invertirlo después en los cosplays o cosas así (Entrevista con Ana, 29.05.10). ${ }^{10}$

Testimonios como éste revelan un proceso de mercantilización que creaba, en un mismo movimiento, un mundo social y diferentes trayectorias de fans, entre ellas, la de los organizadores de eventos y los dueños de emprendimientos de venta de merchandising. En las siguientes secciones consideraré sus experiencias con relación a los objetos o servicios que producían y vendían.

\section{Convertirse en organizador de eventos y en miembro de un staff}

Mientras que Hills (2002) habla de una dialéctica permanente entre valor de uso y valor de cambio que se pone en juego en la relación de los fans con los objetos, para Appadurai (1991) las mercancías representarían un estado de las cosas del que éstas pueden entrar y salir en diferentes momentos de su existencia -lo que él denomina, siguiendo a Kopytoff, su "biografía cultural"-, a partir de su inclusión en sistemas de valores específicos: "Propongo que la situación mercantil en la vida social de cualquier "cosa" se defina como la situación en la cual su intercambiabilidad (pasada, presente o futura) por alguna otra cosa se convierta en su característica socialmente relevante" (Appadurai, 1991:29).

Los procesos de mercantilización y singularización, de entrada y salida de ese estado de mercancía, se vinculan, además, con distintas distribuciones de conocimiento que "puede ser de dos tipos: el conocimiento (técnico, social, estético y demás) que acompaña a la producción de la mercancía, y el conocimiento que acompaña al consumo apropiado de la mercancía” (Appadurai, 1991:6o). Si consideramos a los eventos como mercancías culturales, podemos decir que los organizadores de eventos detentaban y producían esos conocimientos, ya que eran ellos quienes determinaban la fecha del evento, el lugar en el que se realizaría, el precio de las entradas, las actividades durante la jornada; y además, fijaban cronogramas y horarios, distribuían tareas y participaban de la creación de redes de relaciones, con organizadores locales y de otras provincias. En este contexto mercantil, pensando en términos de Appadurai (1991:31), dicho conocimiento era, a la vez, de la producción y del consumo, puesto que quienes se desempeñaban como organizadores habían desarrollado la inquietud por dedicarse a tal actividad a partir de asistir a otros eventos.

10 Luego del contacto inicial en un evento y de la realización de una entrevista en profundidad, el vínculo y la conversación con Ana se mantuvieron durante los siguientes cuatro años. 
La propia participación en esas escenas creaba relaciones, habilidades y saberes necesarios para las tareas de organización, es decir, aprender las formas estandarizadas de hacer las cosas en esos mundos. Daniela, de quien hablé previamente, se convirtió en organizadora luego de haber ganado un concurso de cosplay y de desempeñarse como jurado en otros concursos. Ir a los eventos le sirvió para incorporar conocimientos relativos a su organización:

He ido a casi todos los eventos que se hicieron en Córdoba desde que empecéa ir, y yendo a eventos aprendés muchísimo. Es la primera vez que organizo y la verdad es que es muy fácil para mí, además porque hace rato que venía con ganas de organizar un evento, entonces cuando iba a los eventos no solo disfrutaba, sino que observaba cómo se hacían las cosas, las fallas... Entonces como que me llamaron en el momento justo, porque si me llamaban un año antes no sabía nada. Este último año que estuve yendo, fui a eso, a disfrutar y a ver cómo se hacen las cosas, ver cómo se organizan, de qué se trata cada concurso y demás (Entrevista a Daniela, 2013).

En el caso de otro evento llamado Concomics, sus organizadores viajaron desde México unos meses antes de la fecha de realización del evento para conocer la ciudad y evaluar si era rentable hacer esa inversión. La llegada de una convención internacional que se realizaba en otras ciudades de América Latina era percibida como un signo de progreso, en especial por aquellos que comenzaron a participar de estos circuitos en los años en que tal oferta aún no se había materializado. Como me decía uno de los integrantes del staff:

... ellos van a decidir seguir viniendo o no, en función de si la gente responde o no. Yo a eso ya te lo digo como un poco de cada lado. Me encantaría que la Concomics siga viniendo porque yo como parte del staff quiero que vengan, me hice muy amigo de la gente del staff y me gusta poder decir "soy parte del staff de Concomics", no quiero que sea algo pasajero, quiero seguir siendo el que los represente acá. Pero también soy un chico al que le gusta la onda y que me gustan los eventos (Entrevista a Federico, 21.03.13)."

De estos fragmentos de entrevistas podemos establecer que familiarizarse con el ambiente y la onda era una condición para la producción de los eventos, y por esa razón, como veremos luego, se volvía un marcador que distinguía a aquellos que pertenecían a estos mundos y que tenían una trayectoria reconocida en ellos, de los considerados advenedizos, que solo se interesaban en los eventos "como un negocio". De esta manera, los mejor posicionados para crear este tipo de material eran los propios fans, ya que habían acumulado una experiencia que los volvía conocedores y les daba la sensibilidad para responder satisfactoriamente las demandas del público. En este sentido, es importante notar que los organizadores y los miembros del staff se ubicaban en una franja de entre 23 y 35 años, mientras que las edades de los asistentes reconocían un espectro más amplio, con gran cantidad de niños que concurrían acompañados de sus padres.

Tanto para los organizadores como para el staff, la pasión que sentían por la cultura pop japonesa creaba dificultades para dar lugar a procesos de profesionalización y los ubicaba en una situación contradictoria frente a otros fans. Así, si bien por sus conocimientos se encontraban habilitados para organizar, es decir, poner en movimiento los mundos del animé locales, también se volvían objeto de críticas en caso de que obtuvieran ganancias. Con frecuencia, esas tensiones internas eran resueltas a partir de la asunción de un rol intermedio, como lo expresaba uno de ellos cuando se reconocía como "parte del staff” " "un chico al que le gustan los eventos". Ante mi repregunta, me explicaba qué quería decir con esa distinción:

-Lo decís porque sos aficionado y a la vez parte de una organización...

11 Cuando conversamos, Federico tenía 23 años y estudiaba Licenciatura en Cine y Televisión en la Universidad Nacional de Córdoba. 
-Es que es lo que soy, soy como un ayudante-alumno, ¿me entendés? Porque estoy con los profesores y bancándolos a ellos, pero yo estoy para ayudar a los chicos. En este caso, soy del staff, soy la cara de ellos acá, las consultas me las hacen a mí y yo las transmito allá. Los banco [a los organizadores], los ayudo, soy parte del staff, pero yo también fui un aficionado y también fui un alumno, ¿me entendés? Soy un ayudante-alumno, igual que ellos (Entrevista, 2013).

Tal vez eso aparezca de modo más claro en la trayectoria de uno de los organizadores del Córdoba Anime Fest, que vale la pena de ser descrita puntualmente para analizar los aspectos que mencioné acerca de la socialización en las convenciones vigentes, las edades de los organizadores y su posición de mayor jerarquía en el fandom. En 2010, cuando lo entrevisté por primera vez, tenía 23 años y cursaba estudios en Administración de Empresas en una universidad privada. Trabajaba, además, como empleado de correo y alternaba sus ocupaciones estrictamente laborales con la organización del evento. En ese entonces, me contaba que había creado un foro online y además había desarrollado gran variedad de proyectos, entre ellos, viajar por eventos del país para llevar novedades a Córdoba:

... no únicamente he hecho lo que es el foro -porque ahora está el foro nuevo, que es el Imperio Otaku-, sino que no me he quedado en eso, he hecho la radio, he hecho un evento, ahora estoy con proyectos de hacer una revista, después voy a alquilar un local comercial para que compartamos manga, que vengan después a jugar a la Play [Station]. O sea, siempre estoy en movimiento. A mi me gusta ser una persona que le gusta dar todo, a los chicos darles con todos los gustos (Entrevista, 03.09.10).12

Cuando comentaba acerca de sus comienzos en la tarea de organización se remontaba al período 20052006, en el que empezó a "conocer el movimiento", es decir, a participar de las reuniones que los grupos de fans organizaban en una plaza del centro de la ciudad. En esos años y hasta el 2009, el único evento vigente era el Anime Bash, que se llevaba a cabo en boliches y que había surgido de las gestiones conjuntas de una comiquería y un grupo de fans. Cuando la fiesta pasó a ser organizada por un aficionado de corta edad que carecía de los conocimientos necesarios para ocuparse de esa tarea, ${ }^{13}$ él y otros miembros del grupo empezaron a pensar en la posibilidad de generar otro tipo de oferta para los aficionados al animé locales. Su relato acerca del primer evento muestra algunas prácticas vinculadas a las tareas de organización y, además, revela las tensiones entre organizar eventos "por gusto" y "vivir de esto" que los propios organizadores experimentaban como constitutivas a su rol en esos circuitos:

Me acuerdo de que la primera CAF fue: el sonido me lo prestaron unos amigos, [había un] único stand y era vender comida y bebida, y nada más. Y bueno, la gente caía y les gustaba, les gustó y vieron que yo no tengo ningún local, nada... yo soy una persona muy normal, tengo un trabajo normal, trabajo, estudio, no tengo algo relacionado, que me genere dinero con el animé o un local. No, soy una persona normal que hace eso. Y eso me ha gustado (Entrevista, 2010).

En otro momento de la entrevista definía esa tensión como una oposición entre el amor y el lucro, y establecía que realizaba un estudio de mercado a la hora de planificar cada evento:

... yo trato de darle a la gente lo que le gusta. Es como un estudio de mercado lo que hago a veces, digo yo como administrador de empresas, hago un estudio de mercado y veo lo que a la gente le gusta o lo que necesita y yo trato de dárselo. Es eso lo que hago yo. $Y$ en realidad lo hago sin ningún fin de lucro, yo lo hago por amor porque me gusta organizar y me gusta el movimiento (Entrevista, 2010).

\footnotetext{
12 La entrevista se realizó un año después de habernos conocido en un evento de animé.

13 En 2008, el local comercial que auspiciaba la fiesta fue vendido a uno de sus clientes habituales, quien se encargó de organizar los eventos durante ese año.
} 
Al igual que los emprendimientos de esos mundos, él también empezó con fiestas en casas particulares y luego, progresivamente, decidió realizar un evento propiamente dicho en un salón, con entradas y un programa de actividades. En torno a ese proyecto se montó toda una red de cooperación que incluía a amigos y familiares: en cada edición de la CAF participaba un equipo o staff de amigos que ayudaban en la realización de las distintas actividades, mientras que los gastos corrían por cuenta de él, en tanto que inversor y organizador. Parte de los costos se cubrían con el aporte de los dueños de locales comerciales o pequeños productores, que pagaban un monto específico por el derecho a poner un stand de venta en el salón y/o aparecer en los panfletos publicitarios como auspiciantes. Ese dinero era empleado para pagar los gastos de alquiler del salón, de tal manera que los ingresos provenientes de las entradas se convirtieran en ganancias. Los eventos que se realizaron luego, aunque organizados por otros grupos, tendieron a seguir las convenciones establecidas por este tipo de cooperación mutua entre organizadores y vendedores.

Una trayectoria interesante para nuestro análisis es la del organizador del evento Shibuya, ya que reconocía la mediación del dinero como necesaria para lograr los objetivos propuestos. Al momento de la entrevista tenía 28 años y era dueño de un local comercial que vendía productos asociados con la cultura pop japonesa, donde también se hacían tatuajes. En su caso, estaba familiarizado con las actividades comerciales porque trabajaba en un bar y, además, provenía de una familia de comerciantes vinculados con la venta de indumentaria, discos, y accesorios de rock. El primer evento que organizó tuvo lugar en dicho bar, ubicado en la zona del "ex Abasto" ${ }^{14}$ :

Yo ya tenía el Vampire Club, y en el 2009 hice el evento Anime Explosion. Fue el primero que hice, que lo hice con un amigo, le dije "bueno, nos juntemos, yo tengo un bar, nos juntemos a ver qué onda". Lo ibamos a hacer todo gratis porque la idea era juntarnos. Pero justo se dio la posibilidad de que estaba esta banda, Tamagochi, en ese entonces, pero vivían en otra provincia y necesitábamos plata para [traerlos]. Entonces digo "bueno, cobremos la entrada y de ahí sacamos para Tamagochi y les pagamos". Si bien no iba a ser con un fin de lucro, son cosas que se te presentan (...) Sí o sí tenés que cobrar la entrada para poder financiar eso (Entrevista, 20.02.13). ${ }^{15}$

Distinto de los anteriores, otro de los eventos vigentes por esos años se había realizado a partir de la separación de las tareas de inversión y organización. Esto abría la puerta para la intervención de actores ajenos a esos mundos y que carecían, por lo tanto, de los conocimientos considerados necesarios para la producción de eventos de ese tipo. En la opinión de los organizadores entrevistados, esa innovación constituía una amenaza, en la medida en que se corría el riesgo de transformar las fiestas "en un negocio" y, con el paso del tiempo, incluso los inversores podían llegar a prescindir de los saberes de los fans. Como me comentó uno de ellos:

... yo les dije varias veces a los chicos que una vez que ya sepan cómo se hace el evento, los van a echar. Yo tengo miedo de que los echen. A alguien van a tener, pero van a decir "ah, esto de organizar stands, lo llamo a fulanito que es mi primo y lo organiza", yo creo que lo ven así, como un negocio (Entrevista, 03.07.13).

Aquí se presentan dinámicas de mercantilización y singularización distinguidas por Appadurai (1991), por medio de las cuales una cosa deviene mercancía en un momento dado y luego, insertada en regímenes de valor diferentes, se desmercantiliza. En su etnografía, Tsing (2015) considera ese punto al decir que no hay alienación en la relación entre los recolectores de hongos y sus "trofeos de caza", ya que en un primer momento éstos se asocian a la libertad y al placer de la búsqueda y luego son convertidos en mercancías a través de operaciones

\footnotetext{
14 El "ex Abasto" es una zona relativamente cercana al centro de la ciudad, que comprende gran cantidad de locales bailables. Hasta fines de la década de 1980 fue sede del Mercado de Abasto, de ahí su nombre. Luego del traslado de dicho mercado, los galpones y construcciones remanentes fueron reconvertidos en pubs, bares y boliches.

15 Tamagochi Experiment era una banda de covers de openings y endings de las series de animé que surgió en el año 2005 . Una crónica sobre ese evento se encuentra en una de las páginas de la banda: http://tamagochiexperiment.blogspot.com.ar/2009/o6/anime-explotion-cordoba-30509.html. Acceso en: 10/11/2013.
} 
de traducción realizadas por mediadores. Los compradores, a su vez, acceden a ellos teniendo en mente la construcción de relaciones (Tsing, 2015:121-125). Para los organizadores, si bien los eventos podían constituir mercancías, había una clara distinción entre saber de qué se trataban, conocer a las personas del circuito y ser fan del animé, y tener un interés solo como empresario. "Hacer por amor" y "hacer por dinero", sin embargo, no eran procesos excluyentes, sino que se encontraban en contigüidad, y servían a la construcción de procesos clasificatorios en esos circuitos. Así, la segunda expresión podía ser empleada como categoría acusatoria dirigida a algunos organizadores, mientras que la primera podía ser reservada para explicar la relación propia con los mundos del animé.

Los fans reconocían que el ejercicio de las tareas de organización suponía abocarse a cuestiones que no pasaban por el disfrute, sino que adquirían un matiz laboral. Por esta razón, vinculaban el mayor o menor éxito de los eventos a la edad de los sujetos. Ir como asistente e ir como organizador o miembro del staff imponía diferentes maneras de hacer uso del espacio, y habilitaba distintos tipos de experiencias. Así lo relataba un organizador:

Pasa que un chico de 18, 19 tiene ganas de hacer algo, pero no tiene idea cómo. Es lo que me pasa a mí. Mucha gente me dice "sí, te quiero ayudar". Pero cuando llega el momento de ayudar, me dicen "si querés te ayudo para armar, pero cuando es la fiesta no cuentes conmigo" (...) los chicos más chicos no pueden organizar un evento porque inconscientemente se dan cuenta de que o te atás al evento o te atás a ser público (Entrevista, 2013).

En ese sentido, otro organizador me narraba que a veces era necesario contratar empleados ajenos a la onda para que se ocuparan de trabajar y no se distrajeran con el evento:

Vos no podés mandar a la gente cuando están de onda, cuando les pagás sí. Nosotros somos 22, son amigos. Cinco o seis serán de la onda nomás, porque si tenés gente en el staff que es de la misma onda no te van a rendir lo que esperás que te rindan porque se van a poner a conversar, se van a distraer y después vas a tener medio mundo atrás putéandote porque no hay nadie ayudando en nada. Para un staff tenés que tener gente que no sea del rubro, siempre va a responder mejor porque esa persona va a ir a trabajar y a hacer lo que vos digas que haga (Entrevista, 2013).

En los eventos de animé donde desarrollé mi trabajo de campo, los miembros del staff tenían un vestuario característico que los distinguía del público. Por lo general, consistía en una remera con el logo del evento y el nombre o Nick-name (apodo) de cada uno. Se encargaban de coordinar las actividades, desde la venta de comida hasta el desarrollo de los concursos de dibujo, videojuegos y cosplay, de modo que su ropa funcionaba como un índice de su pertenencia al equipo de organización. Además de ser concebido como una afición o hobby que demandaba esfuerzo y dedicación, para los jóvenes del ambiente pertenecer a un staff era signo de haber alcanzado un mejor posicionamiento a través de la construcción de una relación de confianza con los inversores/ organizadores. La permanencia en uno de esos equipos se constituía en indicio del cambio de posición en el circuito de eventos, en dirección al ejercicio de labores de coordinación de actividades de divertimento que antes habían realizado como asistentes. 


\section{“Compra y venta friki”"16}

En su estudio sociológico sobre el trabajo artístico, Becker (2008) considera como una parte esencial la movilización de recursos, esto es, la producción de los recursos materiales y personales cuya presencia posibilita la creación de las obras consideradas artísticas. La emergencia de fabricantes y proveedores se vincula directamente con la presencia de una demanda determinada, en la medida en que "Si la economía permite y recompensa esa actividad, algunos empresarios considerarán que hasta vale la pena apuntar a un mercado pequeño y minoritario" (Becker, 2008:96). En mayor proporción que los organizadores -cuyo desempeño requería, como vimos, contar con dinero para costear la producción de un evento en caso de los inversores, y de ser conocedor y trabajador en caso de los miembros del staff-, varios de los jóvenes que conocí como asistentes se convirtieron en vendedores de distintos tipos de objetos. Así, comenzaron a participar en esos espacios festivos con su stand de venta, que consistía en una mesa o tablón cubierto de un mantel y poblado de objetos diversos, a menudo adornados por carteles que indicaban el nombre del emprendimiento y tarjetas pequeñas con la dirección y/o su página web, a disposición de compradores y curiosos.

Si entre los años 2009 y 2010 las convenciones contaban con un promedio de diez stands, en 2013 tenían casi cuarenta, lo cual ampliaba las oportunidades de hallar diversas versiones de un mismo objeto. Esto implicaba un marcado contraste con una época anterior en la que, según los entrevistados, era mucho más difícil conseguir cosas. Precisamente, las prácticas de DIY que atravesaban esos mundos tenían que ver, como en la organización de eventos, con el descubrimiento por parte de los sujetos de que podían hacer y construir -individual y colectivamente- aquello que no podían adquirir por internet o que no se encontraba a su disposición en los locales comerciales del centro de la ciudad.

Una motivación semejante a la descrita subyace a la creación de fanzines, AMV, fan art y fan fiction (Jenkins, 2009; 2010; Schott \& Burn, 2007) y al intercambio de cintas grabadas con recitales inéditos, como aparece en la investigación de Cavicchi (1998:74). Esas obras pueden ser interpretadas, como "indicios materiales de la productividad de la cultura de los fans" (Jenkins, 2010:14); y entre ellas, cabe incluir los proyectos laborales que permitían el desarrollo de trayectorias a medio camino entre hobby y trabajo, muchas veces en vías de profesionalización. Con el objetivo de abordar esas trayectorias, la categoría de "pequeños productores" desarrollada por Abercrombie y Longhurst (1998) y citada por Hills (2002) en sus consideraciones sobre la "dialéctica del valor"-, constituye una primera referencia analítica, en tanto describe las experiencias de quienes comienzan a producir aquello que consumen. Para ellos,

'the previous enthusiasm becomes a full-time ocupation' (...), are involved in market-organised relations and are able to use their finely-honed skills to produce material professionally which then can be marketed back to their own fan culture (Abercrombie \& Longhurst, 1998 apud Hills, 2002:5).

En los mundos analizados el panorama era más complejo, ya que la producción de objetos no suponía una posición recortada prolijamente del espectro de los consumidores. Esto ocurría porque muchos se pensaban en camino a la profesionalización, y por el momento concebían sus actividades de organización y venta como hobbies que mantenían junto a su trabajo normal. Además, siguiendo la apuesta de Turner (1977) de considerar el entre, propongo no pensar en una transición consumada desde el entusiasmo (inicial) hacia un oficio (final), o del apego hacia el desapego, sino de un proceso de construcción de sí en el que las pasiones que los sujetos sienten por las mercancías son permanentemente negociadas.

16 "Compra y venta friki” era el nombre de un grupo de Facebook que reunía a personas interesadas en "vender, comprar o intercambiar cosas (...) del ámbito cosplayer, frikie o gamer” La dirección de la página era https://www.facebook.com/groups/200478743356650/ y contaba con 833 miembros. Acceso en: 08/10/2013. 
Para acompañar las narrativas o procesos de tales fans, hecha la salvedad de que los casos no se ajustan completamente a la definición presentada anteriormente, me guiaré por los tipos de proyectos comerciales que reconocí durante mi participación en los circuitos articulados por las convenciones. Uno de ellos se llamaba "Friki Store", y consistía en una tienda virtual de venta de artículos importados. ${ }^{17}$ Su dueño, a quien llamaremos Martín, tenía 28 años y se definía como coleccionista y friki. Participaba con su stand en los eventos y esta actividad era para él "un cable a tierra" y un hobby, en comparación con su trabajo de lunes a viernes en un organismo estatal. El desarrollo de su negocio se vinculaba directamente con su trayectoria como fan del animé desde la infancia, y con su creencia de que un verdadero fan debía tener cosas de las series, coleccionarlas, y volverlas parte de su hogar, como objetos decorativos. De hecho, las figuras que poseía eran para él "pequeños trofeos de la vida" que le servían para recordar escenas de las series y situaciones del pasado en compañía de esos personajes. Así como las series tenían el poder de "enganchar" a los sujetos, este poder también era atribuido a los objetos, que funcionaban como artefactos que posibilitaban la construcción de biografías y trayectorias.

Como sostiene Hennion (2007) a propósito de la acción de aprender a escalar, el gusto es una actividad que se produce en el contacto con los objetos, es decir, en "el momento del surgimiento incierto de una sensación" (2007:5) que involucra la reflexividad presente en una disposición posible de identificar. Las cosas, por su parte, se caracterizan por su capacidad de interrumpir, de imponer una presencia: "Los objetos no están allí, inertes y dispuestos a nuestro servicio. Ellos se entregan a sí mismos, se develan, se imponen sobre nosotros" (Hennion, 2007:10). Este poder de los objetos aparecía en el relato de Martín, cuando hablaba acerca de la relación entre sus series preferidas y la compra de figuras coleccionables, y concluía que eso se debía a que había "una historia detrás de cada objeto para cada persona":

De [la serie] Lupin III tengo figuras porque cuando las veo me hacen acordar a partes y me tiento solo, es más, me estoy tentando ahora de pensar en alguna de las escenas y cómo están hechos los personajes. Lo mismo con otras cosas, con otros juegos y cosas así, que tengo figuras y cosas, y me evoca eso. También por ese lado con lo que hablamos al principio que te decía del tema de las figuras y la gente que quiere tener algo de animé, lo que te acabo de decir recién, cuando ves la figura te evoca algo (...) La figura dentro de todo está viva desde el punto de vista de que vos la podés poner en una pose que te haga acordar a una escena de la serie o del juego, o lo que sea. Entonces cuando lo ves te imaginás, empezás a fantasear (Entrevista con Martín, 18.04.13).

El proyecto del stand emergió dentro de esas prácticas como coleccionista y se manifestó a partir de su propia participación en eventos de animé, realizados desde 2010 en adelante. Ante la presencia de stands y productos similares, como así también de los altos precios de algunos productos en particular, decidió comenzar su propio emprendimiento de venta de figuras y objetos que él mismo compraría. Aquí aparecen, una vez más, las prácticas DIY que tienen a los consumos personales como puntos de partida: "con el tema del stand tuve un criterio muy simple: voy a comprar cosas que yo compraría, mejor dicho, voy a vender cosas que yo compraría. Incluso la mayoría de las cosas que yo vendo, casi siempre tengo una o dos para mí."

Como puede observarse, el desarrollo de un emprendimiento como éste comportaba una visión de lo que los propios fans desearían ver o tener, y se constituía sobre la base de las anticipaciones, propias de un conocedor de esos mundos. En el caso del dueño del emprendimiento que consideramos aquí, luego de tomar la decisión de iniciar un negocio, dicho proceso continuó con la venta de productos a sus amigos; y la opción, finalmente, por incursionar en la venta directa en un stand, a raíz de la invitación del organizador de un evento. En este sentido, el nombre elegido -Friki Store- tenía que ver al mismo tiempo con el tipo de objetos

17 La mayor parte de estos emprendimientos eran tiendas virtuales que permitían abaratar los costos que demandaba tener un local. Se trataba de una tendencia más generalizada, como puede verse en la siguiente nota periodística acerca del tema: González, Laura: "Emprendedores por medio de Facebook", La Voz del Interior, 04/05/2013. http://www.lavoz.com.ar/ciudadanos/emprendedoras-medio-facebook. Acceso en: 09/10/2013. 
que comercializaba y con las cosas que le gustaban. Tal como él lo decía en la entrevista, lo que lo atraía de los eventos era atender a los clientes y "contagiar el frikismo", una emoción que era despertada por cosas que se compraban y vendían en esos ámbitos:

A mí me gusta más la idea de contagiar un poco el frikismo que la idea de venderlo. Obviamente es un negocio y lo vendo, pero independientemente de la venta me gusta más la reacción de la gente cuando ve algo de alguna serie que vieron y dijeron " ¡iahhh!” o de ver algo así, único, raro y decir "me gustaría tener en casa esto o regalárselo a alguien". Bueno, eso en sí. Como te digo, también es parte de la esencia de ver que la gente reacciona ante las mismas cosas que a mi me gustan. (Entrevista, 2013).

Otro tipo de emprendimiento era aquel que se dedicaba a la venta de productos fabricados artesanalmente por sus dueños (fanmade), quienes tenían sus propias páginas web y también participaban de los eventos con sus stands. Uno de ellos era "Escaramaquia Réplicas", que se dedicaba a la venta de "réplicas, remeras y objetos para fans", tal como decía en las tarjetas que sus dueños distribuían y en sus páginas de Facebook. Al momento de la entrevista, uno de ellos tenía 37 años y era diseñador industrial. Su interés por el animé se remontaba a su infancia y la producción de objetos también se había desarrollado en ese período, como una forma de tener aquello que no podía conseguir, o que se encontraba disponible, pero era demasiado caro:

Eso de las maquetas y las réplicas siempre ha sido una especie de ausencia de lo que no se podía comprar, de suplantar lo que no se podía comprar cuando éramos pibes. (...) no estaba la posibilidad, en los últimos 15 años se han podido comprar cosas, antes no. Yo me acuerdo muy claro de haber querido un Mazinger cuando era chico y era un sueldo de mi papá, un sueldo de empleado municipal. Era mucha plata y teníamos una familia grande (Entrevista, 06.05.13).

Decidió crear Escaramaquia luego de que lo despidieran de su trabajo anterior, de manera que, para él, lo que antes era una afición se transformó en un trabajo. A diferencia del caso anterior, aquí la venta de remeras estampadas y de réplicas constituía su única fuente de ingresos, y la participación en el circuito de eventos representaba una instancia casi obligada para tornar conocido su emprendimiento y expandir sus ventas. En el desarrollo de una carrera planteada como profesional, admitía que desprenderse de los objetos que confeccionaba le había llevado tiempo y esfuerzo, por lo que el pasaje del consumo al emprendimiento comercial estuvo atravesado por un aprendizaje sobre cómo relacionarse con lo producido para finalmente venderlo y dejarlo ir:

Ahora siempre digo "me voy a volver a hacer cosas" pero no he tenido tiempo. Tengo algunas, pero tarde o temprano se van. Ya medio que me autoconvencí de que son productos, pero también son cosas que me gustan a mí. No es lo mismo cuando me piden una espada o un arma de un animé que no conozco o no me gusta, sí, lo veo más como un producto y está bien, queda hermoso en un lugar, es atractivo, pero no me atrae. Pero cuando me piden algo que me gusta a mí o es conocido... Inclusive en un tiempo empecé a hacer dos de cada cosa. Pero no, tuve que dejar porque quedaba una terminada y otra a la mitad ocupando espacio, me terminaba olvidando de que estaba eso ahí guardado. (...) Pero me ha pasado con eso, con remeras me pasa todo el tiempo. Es peor aún porque en el ámbito que me muevo yo somos todos afines, hasta musicalmente. Hago una remera y la quiero para mí, pasa que bueno, he aprendido a evitarlo porque si no tendría una cantidad enorme de remeras sin usar, y aparte es un gasto innecesario (...) Y sí, cuesta desprenderse de todo lo que a uno le gusta para que sea vendido (Entrevista, 2013).

Aquí nos encontramos con el tema del afecto que estos objetos despiertan, que tiene que con la historia de los fans, las cualidades sensuales y materiales de los objetos en sí (Hennion, 2007), y con el hecho de haber sido fabricados por ellos mismos, en un proceso afectivo en el que participan las emociones inspiradas por las películas, las series y los mangas. 
Por último, atendiendo a la caracterización de tipos de emprendimientos propuesta con anterioridad, mencionamos los locales comerciales, ubicados principalmente en la zona céntrica de la ciudad, que se ocupaban de vender no solo artículos importados, sino también las cosas que llevaban los pequeños productores. En estos casos, se trataba ya de una opción por una actividad profesional, aunque a semejanza con las historias mencionadas, se enfatizaba que su creación se debía a la decisión de dedicarse a "lo que realmente les gusta". Estos locales tenían sus páginas web, que servían principalmente para difusión, y sus dueños concurrían a los eventos con sus stands; funcionaban también como espacios donde los organizadores de eventos podían realizar fiestas y reuniones para un número reducido de participantes. Entre los ejemplos más significativos o reveladores de esa articulación, podemos citar el caso de dos jóvenes de 23 años que anteriormente frecuentaban los eventos de manera esporádica, porque no residían en la ciudad. Uno de ellos había vivido en una localidad cercana hasta los 18 años y allí formó parte de un grupo que se juntaba todos los viernes a jugar Magic, ${ }^{18}$ motivados por "la buena onda y el amor al juego". Cuando se mudó a Córdoba capital trabajó en una concesionaria de autos y decidió renunciar a ese empleo para concentrar sus esfuerzos en el proyecto del local. Antes de ello, participó de los eventos con un stand, lo que sirvió a modo de preparación para la actividad comercial que quería desarrollar:

Un año antes de que estuviera el local empezamos a participar como stand de los eventos, con el tema de las cartas intercambiables, más que nada Magic, que fue algo que de muy chicos aprendimos a jugar, tenemos mucha experiencia incluso como jugadores relativamente profesionales. Entonces estamos muy metidos en el tema y dijimos "vamos a empezar a sondear el ambiente, ver qué onda". En ese momento no teníamos la variedad de productos que tenemos ahora, era solamente como para ir haciendo una introducción, por así decirlo, y darle temperatura a lo que es el tema del Magic porque en Córdoba había mucha gente que en algún momento jugó, que le interesaba pero que no tenía dónde comprar ni dónde aprender, como que era algo que quedaba muy incómodo porque no hay un lugar que comercialice esto ni mucho menos que te enseñe a jugar. (Entrevista, 16.06.13).

De acuerdo con su relato, su hobby se había convertido en una profesión, aunque eso no impedía que encontrara momentos de ocio en el trabajo, ya que después de todo, siempre estaba entre amigos:

En mi caso sigue siendo mi hobby y mi trabajo, pero son dos momentos divididos porque no es lo mismo la parte de trabajo cuando estoy vendiendo Magic que la parte de hobby cuando estoy jugando Magic porque me gusta. Si bien se desarrollan adentro del local, son dos momentos diferentes donde no está [el] que está trabajando, sino que está el que la está pasando bien. Todas las personas que trabajan acá tienen por lo menos un hobby que se desarrolla acá adentro, porque tienen que tener la capacidad de poder enseñarles a los que quieren aprender (Entrevista, 2013).

En resumen, de las historias descritas realizamos una clasificación de proyectos en: locales comerciales -que cuentan con páginas web-y locales exclusivamente virtuales. Si consideramos el tipo de objetos que comercializan, pueden dividirse en: manufacturados (importados), artesanales o ambos. La articulación entre los diferentes emprendimientos y la escena de eventos daba lugar a una ecúmene mercantil (Appadurai, 1991), y también a procesos de reflexión por parte de los fans respecto a sus carreras, que oscilaban entre actividades de tiempo libre y actividades laborales. Incluso, como vimos, en los casos en que dichas tareas eran concebidas como parte de un quehacer profesional, la línea que separaba esos dos planos era porosa y había un permanente pasaje entre ambos. Esto se daba a partir de la distinción entre momentos durante la jornada de trabajo, o de la fabricación de copias de determinados productos que se destinaban para uso personal.

Las prácticas de compra y venta, propias del modo en que se tejían las redes en los mundos del animé acompañado, estaban atravesadas por los afectos que los objetos generaban, los recuerdos que éstos traían a la memoria y las relaciones de amistad que se formaban, de tal manera que la profesionalización requería una

18 Magic: The Gathering es un juego de cartas coleccionables creado en 1993, que reúne a una comunidad global de jugadores en torneos oficiales y en espacios de encuentro informales. 
transformación del vínculo que cada uno tenía con dichos objetos para aprender a verlos como mercancías. Asimismo, este trabajo sobre sí también era un trabajo sobre la relación con los otros, quienes debían aprender a concebir la labor de estos pequeños productores en tanto ocupación laboral y no como hobby.

\section{Hecho por fans, para fans}

Vendedores y organizadores daban forma a un mundo, proveyendo recursos materiales y personales que se volvían parte del modo de hacer usual, esto es, de las convenciones vigentes. A lo largo de este artículo hemos visto cómo esas interacciones, generalmente comerciales, hacían lo que decían hacer-negocios, transaccionespero también algo más: generaban relaciones y ponían en juego afectos, construían posiciones, carreras y redes. El análisis de las trayectorias de fans y de sus narrativas respecto al desarrollo de proyectos de organización y venta de productos muestra los procesos de construcción de sí que son realizados para, valga la redundancia, procurar construir, de manera paulatina, una posición como profesionales en esos mundos.

En su estudio sobre las carreras de músicos de baile, Becker (2009) sostiene que la definición del éxito profesional se vincula con las relaciones que éstos establecen al interior de su familia, con otros músicos y con agentes marginales, es decir, con empresarios que, a juicio de dichos músicos, tienen un interés exclusivamente comercial: "Es posible pensar una carrera exitosa como una serie de escalones (...) donde cada escalón es consecuencia del patrocinio, un desempeño exitoso y el establecimiento de relaciones provechosas" (2009:129). En los mundos del animé de Córdoba -y aparentemente esto es válido en varios casos, como pude observar a partir del diálogo con fans de otras provincias-, las carreras de emprendedores surgían principalmente de trayectorias previas como fans, de modo que las mercancías que producían y vendían se destinaban al mismo grupo del que ellos formaban parte. La única figura que podría ser asimilada a la del empresario de la música era la del inversor que, ajeno a estos códigos y "mapas de afecto" (Grossberg, 1992), veía la creciente convocatoria de los eventos solo desde el punto de vista de una inversión rentable.

Los organizadores y vendedores asumían una posición intermedia entre hobby y trabajo, en la cual las pasiones que sentían por los objetos que vendían o los servicios que prestaban debían ser continuamente negociadas. Así, volverse profesional requería aprender a concebir las propias prácticas como emprendimientos, y los objetos, producidos y vendidos, como mercancías. Para ser parte de una organización se debía aprender que, durante esas jornadas, los miembros del staff trabajaban y no podían disfrutar del evento permanentemente, como si fueran parte del público. Claro que a menudo se abría un espacio para que el disfrute asociado al hobby se manifestara, ya sea a través de hacer cosplay, de "contagiar el frikismo", de jugar Magic o brindar talleres, que se volvían reuniones de amigos. De esta manera, las historias narradas nos muestran que los análisis relativos a la dialéctica del valor y a la profesionalización se vuelven comprensibles si se tienen en cuenta las experiencias de los fans, la creación de mundos sociales anclados localmente y las trayectorias apasionadas que ponen en juego distintos modos de relacionarse con las mercancías (Díaz, 2014).

García Canclini y Urteaga (2012:12) analizan la relación entre economía, desarrollo social e innovaciones culturales a partir del estudio de la emergencia de nuevos empleos, redes sociales y prácticas creativas por parte de jóvenes mexicanos. Los contextos que describen -gestados por artistas visuales, editores y músicos independientes- tienen en común la producción de "formas complementarias de aprendizaje vinculadas a la capacidad de asociación y trabajo colectivo" (2012:33-34), entre otros aspectos. Una literatura a la que tuve acceso más recientemente tematiza el fenómeno del emprendedorismo y lo coloca en la clave de procesos de autotransformación individual en los que intervienen motivaciones éticas y que conducen a la creación de un yo neoliberal (Fridman, 2019:20-21). 
En los casos de fabricantes y vendedores de objetos, como también de los organizadores de eventos de animé, la percepción sobre lo que a ellos les gustaba consumir y experimentar como público; la formación recibida en espacios educativos formales, trabajos ocupacionales y en las propias convenciones; $y$ las relaciones que eran capaces de movilizar, constituían una constelación de factores que creaban las condiciones para iniciar proyectos propios, que con el tiempo podían transformarse en empleos propiamente dichos. Al organizar y vender, los fans no solo se ponían en contacto entre sí, sino también con sus objetos queridos y con las historias detrás de los mismos, que incluían tanto las tramas narrativas de series e historietas, como los procesos personales de apego y desarrollo de afectos por un conjunto específico de mercancías. Eso, a su vez, reforzaba la opción por dar continuidad a sus proyectos laborales, que se fundamentaban así en el gusto y el amor por la cultura pop japonesa.

En este artículo hemos analizado historias de fans del manga y el animé que desarrollaron distintos proyectos: algunos eran pensados como actividades de tiempo libre que permitían obtener un pequeño ingreso, mientras que otros implicaban opciones profesionales en unos mundos que ellos ya conocían en tanto que consumidores, espectadores y asistentes. El análisis minucioso de los sentidos atribuidos a las prácticas de producción de objetos y eventos, como también a los procesos de profesionalización entre fans permite comprender más ampliamente el papel crucial desempeñado por afectos y pasiones en la conformación de subjetividades y sociabilidades juveniles. De la misma manera, abre el camino para una concepción de los eventos y convenciones de animé como sitios que habilitan -y en los que se realizan- procesos de construcción de sí de los fans, y no solo como instancias expresivas de unas identidades que supuestamente existirían de antemano. Esto pone de manifiesto el intenso trabajo reflexivo implicado en la reformulación de los vínculos con objetos amados y admirados, una vez que éstos pasan a estar cada vez más asociados a la esfera laboral.

Sumisión: 15 de mayo de 2017

Aceptación: 25 de julio de 2019

Revisión: Federico Lavezzo

\section{Referencias bibliográficas}

APPADURAI, Arjun. 1991. [1986]. “Introducción: Las mercancías y la política del valor”. In: La vida social de las cosas. Perspectiva cultural de las mercancías. México D.F.: Grijalbo. pp. 17-81.

BECKER, Howard S. 2009. Outsiders. Hacia una sociología de la desviación. Buenos Aires: Siglo XXI Editores. . 2008 [1982]. Los mundos del arte. Sociología del trabajo artístico. Bernal: Universidad Nacional de Quilmes.

BENNETT, Andy; PETERSON, Richard A. 2004. Music Scenes. Local, Translocal and Virtual. Nashville (Tennessee): Vanderbilt University Press.

BENZECRY, Claudio E. 2012. El fanático de la ópera. Etnografía de una obsesión. Buenos Aires: Siglo XXI Editores.

BLÁZQUEZ, Gustavo. 2009. Músicos, mujeres y algo para tomar. Los mundos de los cuartetos en Córdoba. Córdoba: Recovecos. 
BUKATMAN, Scott. 1994. “X Bodies: The Torment of the Mutant Superhero”. In: R. Sappington; T. Stallings (eds.), Uncontrollable Bodies: Testimonies of Identity and Culture. Seattle: Bay Press. pp. 92-129.

CAVICCHI, Daniel. 1998. Tramps Like Us. Music and Meaning among Springsteen Fans. New York: Oxford University Press.

DE CERTEAU, Michel. 2000 [1990]. La invención de lo cotidiano 1. Artes de hacer. México: Universidad Iberoamericana.

DÍAZ, María Cecilia. 2014. Trajetórias apaixonadas. Uma etnografia entre fãs da cultura pop japonesa em Córdoba, Argentina. Dissertação de Mestrado apresentada ao Programa de Pós-Graduação em Antropologia Social, Museu Nacional, Universidade Federal do Rio de Janeiro (Dissertação). Mimeo.

ELIAS, Norbert; DUNNING, Eric. 1992. "La búsqueda de la emoción en el ocio". In: Deporte y ocio en el proceso de la civilización. México, Madrid, Buenos Aires: Fondo de Cultura Económica. Páginas 83-115.

FRIDMAN, Daniel. 2019. El sueño de vivir sin trabajar. Una sociología del emprendedorismo, la autoayuda financiera y el nuevo individuo del siglo XXI. Buenos Aires: Siglo XXI Editores.

GARCÍA CANCLINI, Néstor; URTEAGA, Maritza (Coords.). 2012. Cultura y desarrollo. Una visión crítica desde los jóvenes. Buenos Aires: Paidós.

GONZÁLEZ, Laura. 2013. "Emprendedores por medio de Facebook", La Voz del Interior, 04/05/2013.

Recuperado de: http://www.lavoz.com.ar/ciudadanos/emprendedoras-medio-facebook. Fecha: 07/05/2013.

GRAY, Jonathan; SANDVOSS, Cornel; HARRINGTON, C. Lee. 2007. "Introduction: Why Study Fans?" In: Fandom. Identities and Communities in a Mediated World. New York and London: New York University Press. pp. 1-16.

GROSSBERG, Lawrence. 1992. "Is There a Fan in the House? The Affective Sensibility of Fandom". In: L. Lewis (ed.), The Adoring Audience. Fan Culture and Popular Media. London \& New York: Routledge. pp. $50-65$.

HENNION, Antoine. 2007. “Those things that hold us together". Cultural Sociology, I(I): 97-114.

HILLS, Matt. 2002. Fan Cultures. London and New York: Routledge.

ITO, Mizuko. 2012. "Introduction”. In: M. Ito, D. Okabe, I. Tsuji (eds.), Fandom Unbound: Otaku Culture in a Connected World. New Haven \& London: Yale University Press. pp. xi-xxxi.

JENKINS, Henry. 2009 [2006]. Fans, blogueros y videojuegos. La cultura de la colaboración. Barcelona: Paidós. . 2010 [1992]. Piratas de textos. Fans, cultura participativa y televisión. Barcelona: Paidós.

KELLY, William W. 2004. "Introduction: Locating the Fans". In: Fanning the Flames. Fans and Consumer Culture in Contemporary Japan. Albany: State University of New York Press. pp. 1-17.

LAMERICHS, Michelle. 2013. "The cultural dynamic of doujinshi and cosplay: Local anime fandom in Japan, USA and Europe". Participations. Journal of Audience \& Reception Studies, 10(1): 154-176.

LOURENÇO, André Luiz Correia. 2009. Otakus. Construção e representação de si entre aficionados por cultura pop nipônica. Tese de Doutorado apresentada ao Programa de Pós-Graduação em Antropologia Social, Museu Nacional, Universidade Federal do Rio de Janeiro. Mimeo.

LUYTEN, Sonia Maria Bibe (comp.). 2006. Cultura Pop Japonesa. Mangá e Animê. São Paulo: Hedra.

PAPALINI, Vanina. 2006. Anime. Mundos tecnológicos, animación japonesa e imaginario social. Buenos Aires: La Crujía Ediciones.

SCHODT, Frederik L. 1983. Manga! Manga! The World of Japanese Comics. New York: Kodansha.

SCHOTT, Gareth; BURN, Andrew. 2007. "Fan-Art as a Function of Agency in Oddworld Fan-Culture”. In: A.

Clarke, G. Mitchell (eds.), Videogames and Art. Bristol, UK/ Chicago, USA: Intellect. pp. 238-254. 
TAMAGAWA, Hiroaki. 2012. "Comic Market as a Space for Self-Expression in Otaku Culture". In: M. Ito, D. Okabe, I. Tsuji (eds.), Fandom Unbound: Otaku Culture in a Connected World. New Haven \& London: Yale University Press. pp. 107-132.

TSING, Anna. 2015. "From Gifts to Commodities-and Back". In: The Mushroom at the End of the World. On the Possibility of Life in Capitalist Ruins. Princeton and Oxford: Princeton University Press. pp. 121-130.

TURNER, Víctor. 1977. “Variations on a theme of liminality”. In: S. F. Moore;, B. G. Myerhoff (eds.), Secular Ritual. Assen: Van Gorcum \& Comp. pp. 36-52.

VELHO, Gilberto. 1981. "Projeto, Emoção e Orientação em Sociedades Complexas”. In: Individualismo e Cultura: Notas para uma Antropologia da Sociedade Contemporânea. Rio de Janeiro: Zahar Editores. pp. 13-37. YUDICE, George. 2007. Nuevas tecnologías, música y experiencia. Barcelona: Gedisa.

\section{María Cecilia Díaz}

Becaria de posdoctorado del Consejo Nacional de Investigaciones Científicas y Técnicas (CONICET), con lugar de trabajo en el Instituto de Humanidades, Universidad Nacional de Córdoba (IdH/UNC). Pesquisadora en el Centro de Investigaciones de la Facultad de Filosofía y Humanidades de la Universidad Nacional de Córdoba (CIFFyH/UNC) y profesora asistente en las materias Teoría Antropológica I e Historia Social Argentina de la Licenciatura en Antropología (FFyH/UNC). https://orcid.org/oooo-0002-3874-3286

E-mail: mcecilia.diaz@gmail.com 